\title{
What Happened to Risk Management During the 2008-09 Financial Crisis?
}

\author{
Michael McAleer \\ Econometric Institute \\ Erasmus University Rotterdam \\ and \\ Department of Applied Economics \\ National Chung Hsing University \\ Taiwan
}

Juan-Angel Jimenez-Martin

Department of Quantitative Economics

Complutense University of Madrid

Teodosio Pérez-Amaral

Department of Quantitative Economics

Complutense University of Madrid

July 2009

\begin{abstract}
When dealing with market risk under the Basel II Accord, variation pays in the form of lower capital requirements and higher profits. Typically, GARCH type models are chosen to forecast Value-at-Risk (VaR) using a single risk model. In this paper we illustrate two useful variations to the standard mechanism for choosing forecasts, namely: (i) combining different forecast models for each period, such as a daily model that forecasts the supremum or infinum value for the VaR; (ii) alternatively, select a single model to forecast VaR, and then modify the daily forecast, depending on the recent history of violations under the Basel II Accord. We illustrate these points using the Standard and Poor's 500 Composite Index. In many cases we find significant decreases in the capital requirements, while incurring a number of violations that stays within the Basel II Accord limits.
\end{abstract}

Keywords: Risk management, violations, aggressive risk strategy, conservative risk strategy, value-at-risk forecasts.

JEL Classifications: G32, G11, G17, C53, C22

* The first author is grateful to the Australian Research Council for financial support. The second author wishes to thank the Secretaría de Estado de Universidades of Spain through project SEJ206-14354 and Complutense University through project UCM-940063, and the third author wishes to thank the Secretaría de Estado de Universidades of Spain through project ECO2008-06091/ECON. 


\section{Introduction}

A financial crisis occurs when there is a significant fall in stock prices and a marked increase in the uncertainty about the value of financial assets. A crisis may also be accompanied by panic, which can be contagious. During a financial crisis, the risks associated with investing increase substantially. The financial crisis of 2008-09 has left an indelible mark on economic and financial structures worldwide, and left an entire generation of investors wondering how things could have become so bad. Many questions have been asked about whether appropriate regulations were in place, especially in the USA, to permit the appropriate monitoring and encouragement of (possibly excessive) risk taking.

The Basel II Accord (see Basel Committee on Banking Supervision (1996)) was designed to monitor and encourage sensible risk taking by using appropriate models of risk to calculate Value-at-Risk (VaR) and subsequent daily capital charges. However, the Basel II Accord does not apply to the USA.

$\mathrm{VaR}$ is defined as an estimate of the potential loss to be expected over a given period, and is a standard tool in financial risk management. It has become especially important following the 1995 amendment to the Basel Accord, whereby banks and other Authorized Deposit-taking Institutions (ADIs) were permitted (and encouraged) to use internal models to forecast daily VaR (see Jorion (2000) for a detailed discussion). The last decade has witnessed a growing academic and professional literature comparing alternative modelling approaches to determine how to measure VaR, especially for large portfolios of financial assets.

The amendment to the initial Basel Accord was designed to encourage and reward institutions with superior risk management systems. A back-testing procedure, whereby actual returns are compared with the corresponding $\mathrm{VaR}$ forecasts, was introduced to assess the quality of the internal models used by ADIs. In cases where internal models lead to a greater number of violations than could reasonably be expected, given the confidence level, the ADI is required to hold a higher level of capital (see Table 1 for the penalties imposed under the Basel II Accord). Penalties imposed on ADIs affect profitability directly through higher capital charges, and indirectly through the imposition of a more stringent external model to forecast $\mathrm{VaR}$. This is one reason why financial managers may prefer risk management strategies that are passive and conservative rather than active and aggressive. 
Excessive conservatism can have a negative impact on the profitability of ADIs, as higher daily capital charges are subsequently required. Therefore, ADIs should perhaps consider a strategy that allows an endogenous decision as to how many times ADIs should violate in any financial year (for further details, see McAleer and da Veiga (2008a, 2008b), McAleer (2008), Caporin and McAleer (2009), and McAleer et al. (2009a)). This paper suggests alternative aggressive and conservative risk management strategies that can be compared with the use of one or more models of risk throughout the estimation and forecasting periods. We also discuss the strategy of choosing one risk model at the beginning of the period, and subsequently modifying the forecast depending on the recent history of violations of the model (see McAleer et al. (2009b)).

In this paper we define risk management in terms of choosing sensibly from a variety of risk models. We discuss the selection of optimal risk models by considering a combination of alternative risk models, and modifying the forecasts of a given risk model depending on the recent history of violations of the model. We evaluate the effects of the Basel II Accord on risk management, and how risk management strategies performed during the 2008-09 financial crisis.

These issues are illustrated using Standard and Poor's 500 Composite Index, with an emphasis on how risk management practices were encouraged by the Basel II Accord regulations during the financial crisis.

\section{The fast recession of 2008-09 in perspective.}

The recession of 2008-09 is undoubtedly severe, but not as much as the Great Depression. During the Great Depression of 1928-1934, Standard and Poor's 500 Composite $^{1}$ Index

\footnotetext{
${ }^{1}$ Some changes in the definition of the S\&P500 index over time:
}

1923 -- Standard de Poor's develops its first stock market indicators. The new stock indices cover 26 industry groups and 233 companies. Also, S\&P introduces base-weighted aggregate technique to gauge stock market performance.

1926 -- Standard \& Poor's creates a 90 Stock Composite Price Index, comprising 50 Industrials, 20 Rails and 20 Utilities. The new composite has a base period of 1926=100 and is calculated and published weekly. Historical values are available going back to 1918. The "233" and the industry group indices are re-based to 1926=100 and are calculated and published weekly.

- 1928 -- Standard \& Poor's 90 Stock Composite Price Index is calculated and published daily. 
(S\&P500) and the Dow Jones Industrial Average (DJIA), using daily data for the period $3 / 1 / 1928-1 / 7 / 2009$, fell by $86.18 \%$ and $89.19 \%$, from a peak of $6 / 9 / 1929$ to a trough of 1/6/1932, and a peak of 3/9/1929 to a trough of 8/7/1932, respectively, whereas the comparable figures for 2008-09 for S\&P 500 and DJIA were falls of 53.25\% and $49.86 \%$ from a peak of 3/1/2008 to a trough of $9 / 3 / 2009$, and from a peak of $2 / 5 / 2008$ to a trough of 9/3/2009, respectively.

Figure 1. Daily levels of the DJIA and S\&P500.

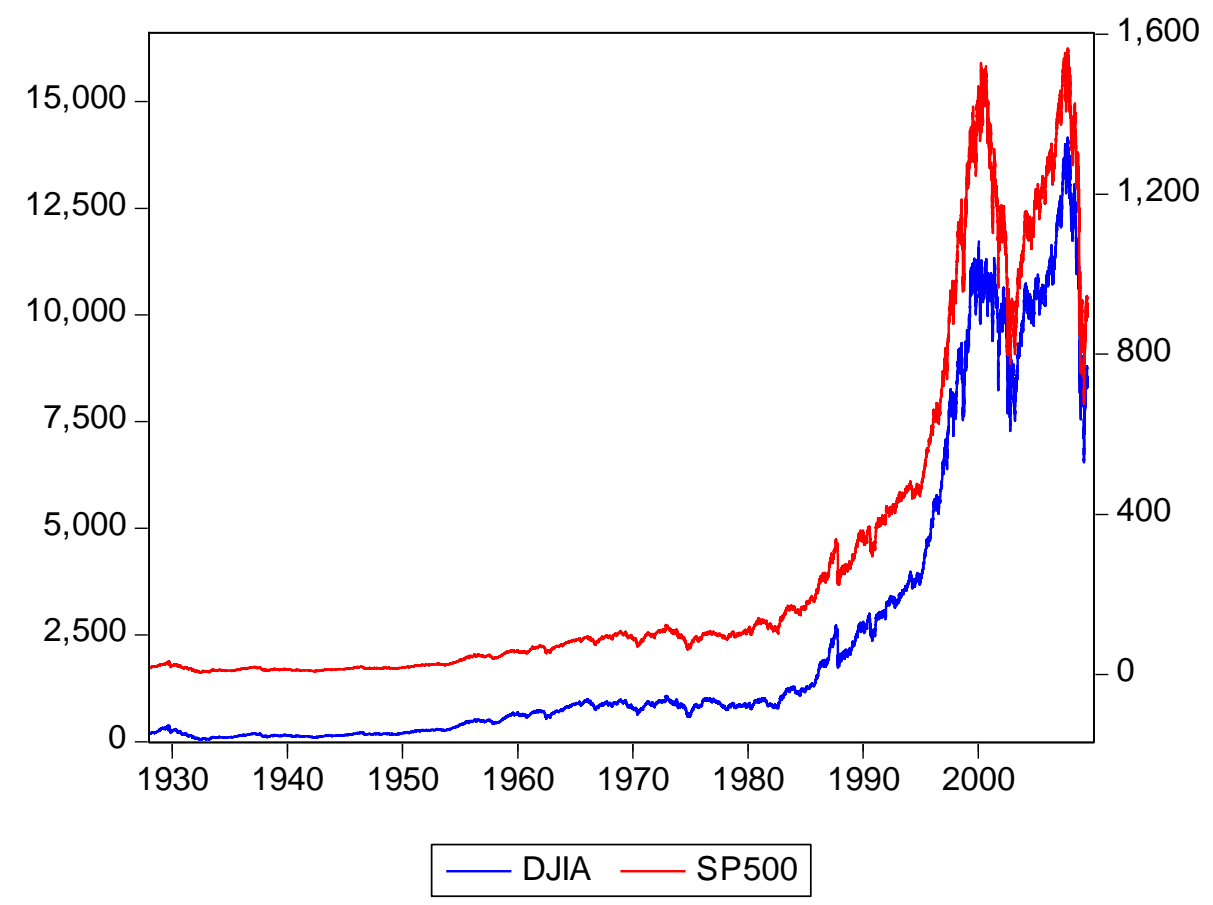

The average daily falls in returns of S\&P500 and DJIA were $0.23 \%$ and $0.25 \%$ during the Great Depression, from a peak of 6/9/1929 to a trough of 1/6/1932, and from a peak of 3/9/1929 to a trough of 8/7/1932, respectively, while the average daily falls in returns of S\&P500 and DJIA were $0.25 \%$ and $0.32 \%$ in $2008-09$, from a peak of 3/1/2008 to a trough of

- 1941 -- The "233" grows to 416, comprising 72 industry sub-groups. The new "416" and the 90 Stock Composite are re-based to 1935-39=100

- 1957 -- The "416" becomes the Standard \& Poor's 500 Composite Stock Price Index. Thanks to technological advancements, computers are introduced and permit the "500" to be calculated and disseminated at one-minute intervals throughout the trading day. In order to create a lengthy historical time series, the new "500" is linked to the 90 Stock Composite Price Index-daily S\&P500 Index prices become available back to 1928. The original "233" and "90" stock indices have evolved into the modern "500". The "500" now consists of 425 Industrials, 60 Utilities and 15 Rails, and has a base period of $1941-43=10$. 
$9 / 3 / 2009$, and from a peak of $2 / 5 / 2008$ to a trough of $9 / 3 / 2009$, respectively, as illustrated in Figure 2.

Figure 2. Daily Returns of the DJIA and S\&P500.

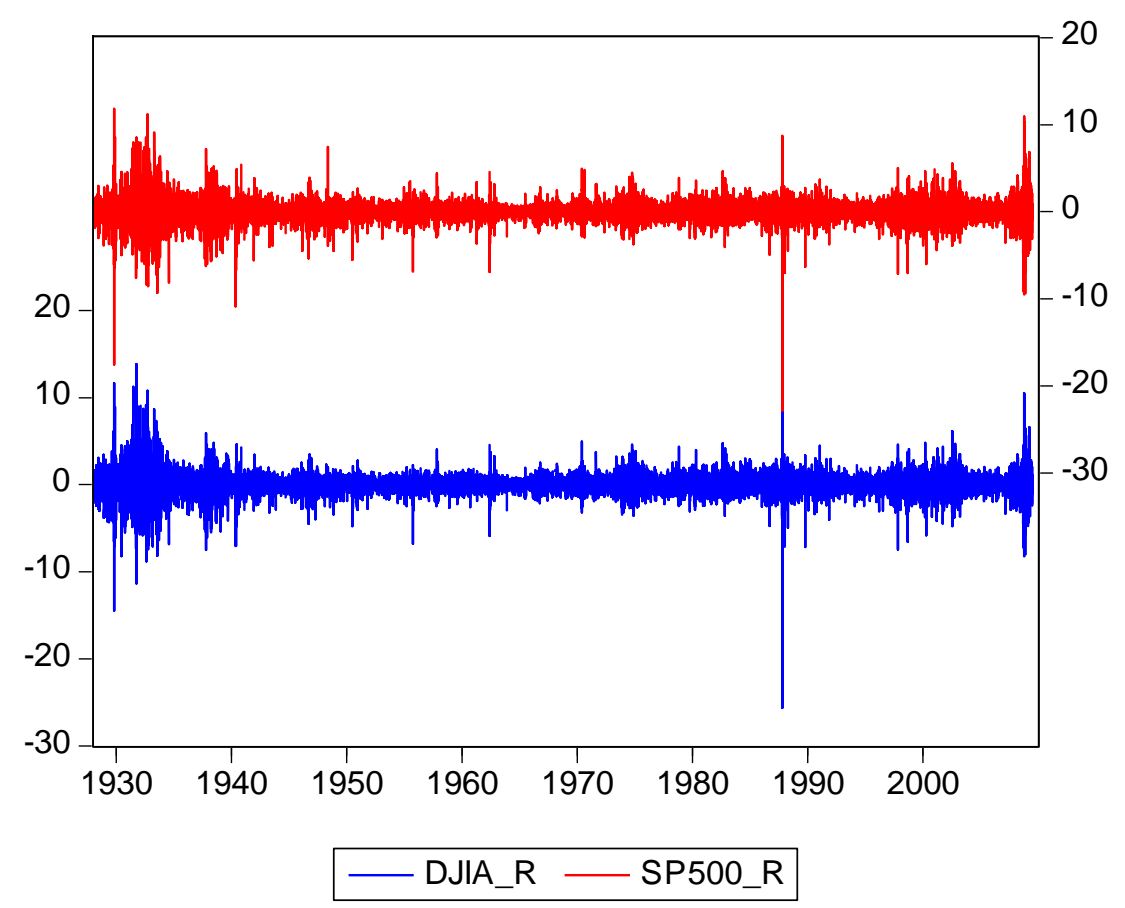

The standard deviation of S\&P500 and DJIA returns reached 15\% and $14 \%$ during the Great Depression, respectively, while in 2008-09 both indexes reached only $11 \%$, as illustrated in Figure $3 .^{2}$

2 On 19 October 1987 (Black Monday) stock markets crashed and fell a huge value in a very short time. As shown in Figure 1, the S\&P500 and the DJIA fell by 23\% and 26\% just in one day, respectively. The standard deviation of both S\&P500 and DJIA returns reached 25.5\%. The Black Monday decline was the largest one-day percentage decline in stock market history. 
Figure 3. Standard Deviation of Daily Returns of the DJIA and S\&P500.

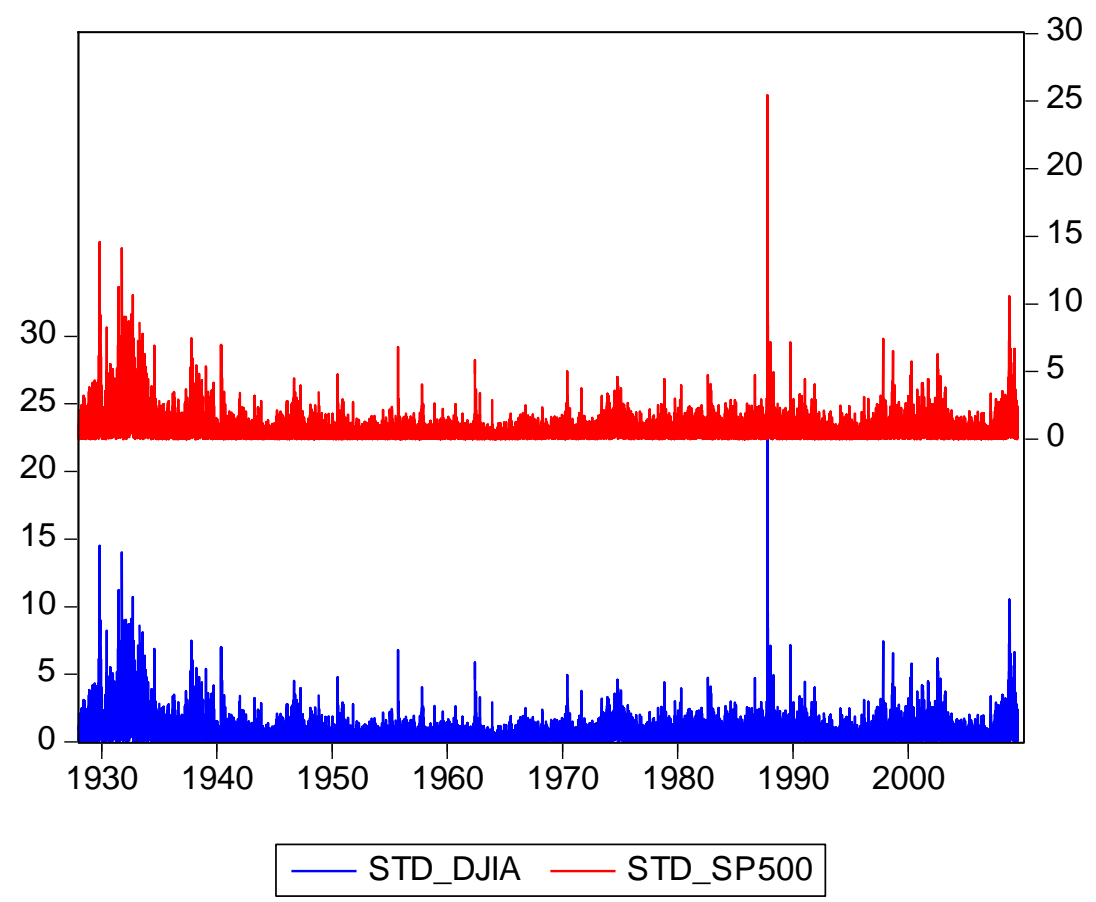

A caveat is that the Great Depression lasted for 6 years while the current depression has been in place for less than a year and may not be over yet (as of July 2009). The 2008-09 depression is less pronounced but somewhat faster than the Great Depression.

The DJIA and S\&P500 indexes are very highly correlated with each other, as seen in Table 1, and tell a similar story in levels, returns and volatility. The use of either is likely to be sufficient for analysing the issues at hand.

Table 1. Correlations between DJIA and S\&P500

\section{CORRELATIONS DAILY}

$\begin{array}{ll}\text { Index (level) } & 0.996068 \\ \text { Return } & 0.940417 \\ \text { Standard Deviation } & 0.999212\end{array}$

As we have seen, the indexes fell by around 90\% during the Great Depression, while they decreased by around 54\% during the 2008-09 crisis. Volatility reached 15\% during the Great Depression while it reached 11\% during the 2008-09 crisis. The Great Depression was around 5 times deeper in terms of prices and 36\% bigger in terms of volatility. 
Once we have placed the 2008-09 crisis into greater perspective, we will be able to discuss how market risk has been managed during the 2008-09 crisis under the Basel II Accord.

\section{Risk management during the 2008-09 financial crisis under the Basel II Accord.}

When ADIs manage risk within the framework of the Basel II Accord, they can choose a model of risk for predicting their VaR. Then they have to communicate their forecasts on a daily basis to the relevant monetary authority.

The ADIs usually choose ARCH-type models (such as GARCH, GJR, EGARCH, and EWMA) that relate future risk to current and past risk (for a discussion of these and other models, see McAleer et al, (2009b)).

The Basel II Accord stipulates that daily capital charges (DCC) must be set at the higher of the previous day's VaR or the average VaR over the last 60 business days, multiplied by a factor $(3+k)$ for a violation penalty, wherein a violation involves the actual negative returns exceeding the $\mathrm{VaR}$ forecast negative returns for a given day:

$$
D C C_{t}=\sup \left\{-(3+k) \overline{\mathrm{VaR}}_{60}, \quad-\mathrm{VaR}_{t-1}\right\}
$$

where

$D C C=$ daily capital charges, which is the higher of $-(3+k) \overline{\mathrm{VaR}}_{60}$ and $-\mathrm{VaR}_{t-1}$,

$V a R_{t}=$ Value-at-Risk for day $t$,

$\operatorname{VaR}_{t}=\hat{Y}_{t}-z_{t} \cdot \hat{\sigma}_{t}$,

$\overline{\mathrm{VaR}}_{60}=$ mean $\mathrm{VaR}$ over the previous 60 working days,

$\hat{Y}_{t}=$ estimated return at time $\mathrm{t}$,

$z_{t}=1 \%$ critical value of the distribution of returns at time $t$,

$\hat{\sigma}_{t}=$ estimated risk (or square root of volatility) at time $t$,

$0 \leq k \leq 1$ is the Basel II violation penalty (see Table 2). 
Table 2. Basel II Accord Penalty Zones

\begin{tabular}{|l|c|c|}
\hline Zone & Number of Violations & $\mathrm{k}$ \\
\hline Green & 0 to 4 & 0.00 \\
\hline Yellow & 5 & 0.40 \\
& 6 & 0.50 \\
& 8 & 0.65 \\
& 9 & 0.75 \\
& $10+$ & 0.85 \\
\hline Red & 1.00 \\
Note: The number of violations is given for 250 business days. \\
The penalty structure under the Basel II Accord is specified for \\
the number of violations and not their magnitude, either \\
individually or cumulatively.
\end{tabular}

The multiplication factor (or penalty), $k$, depends on the central authority's assessment of the ADI's risk management practices and the results of a simple back test. It is determined by the number of times actual losses exceed a particular day's VaR forecast (Basel Committee on Banking Supervision (1996)). The minimum multiplication factor of 3 is intended to compensate for various errors that can arise in model implementation, such as simplifying assumptions, analytical approximations, small sample biases and numerical errors that tend to reduce the true risk coverage of the model (see Stahl (1997)). Increases in the multiplication factor are designed to increase the confidence level that is implied by the observed number of exceptions to the 99 per cent confidence level, as required by the regulators (for a detailed discussion of VaR, as well as exogenous and endogenous violations, see McAleer (2008), Jiménez-Martin et al. (2009), and McAleer et al. (2009b)).

This backtesting procedure intends to encourage appropriate risk management by ADIs, while ensuring their liquidity and solvency. In the next section we discuss strategies that can be 
adopted by the ADIs to enhance risk management practices by minimizing their daily capital charges while restricting the number of violations to lie within the Basel II Accord limits.

\section{Proposals for sophisticating the forecasts of VaR to minimize DCC within Basel II.}

In this section, the forecast values of $\mathrm{VaR}$ for different forecast models and daily capital charges are analysed before and during the 2008-09 financial crisis.

In Figure 4, VaR forecasts are compared with S\&P500 returns for the period 2 January, 2008 through to 2 July 2009. The vertical axis represents returns, while the horizontal axis represents time. Returns of S\&P500 are given as the upper blue line that fluctuates around zero. The upper red line represents the infinum of the VaR calculated for individual models of volatility (VAR upperbound), which reflects an aggressive risk management strategy, whereas the lower green line represents the supremum of the VaR calculated for the individual models of volatility (VAR lowerbound), which reflects a conservative risk management strategy. These two lines correspond to a combination of alternative risk models (see McAleer et al. (2009b) for further details). 
Figure 4. VaR for S\&P500 Returns, 2 January, 2008 -2 July, 2009

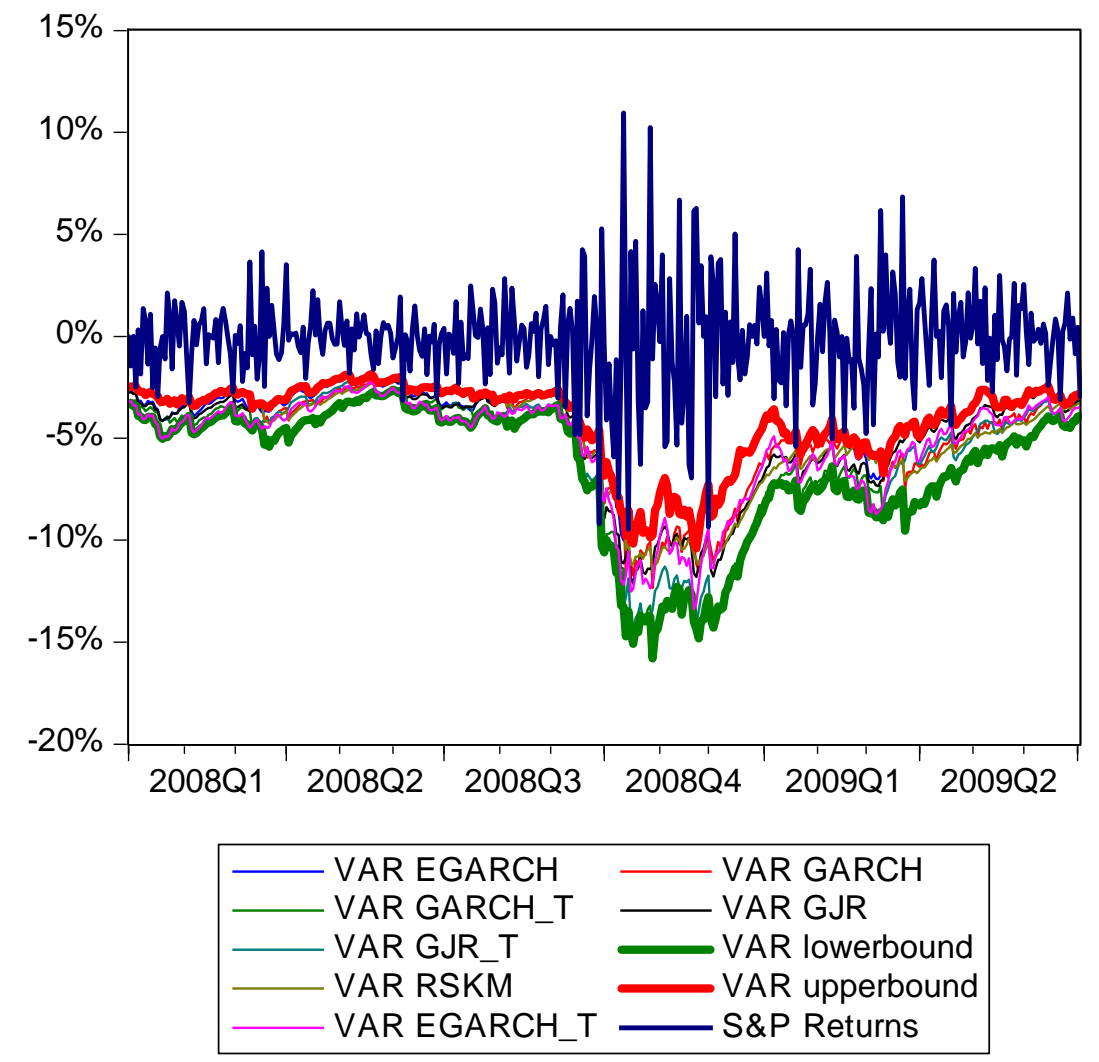

As can be seen in Figure 4, VaR forecasts obtained from the different models of volatility have fluctuated, as expected, during the first few months of 2008. It has been relatively low, at below 5\%, and relatively stable between April and August 2008. Around September 2008, VaR started increasing until it peaked in October 2008, between $10 \%$ and $15 \%$, depending on the model of volatility considered. This is essentially a five-fold increase in VaR in a matter of two months. In the last two months of 2008 , VaR decreased to between $5 \%$ and $8 \%$, which is still twice as large as it was just a few months earlier. It has continued decreasing in the first 6 months of 2009, towards values similar to those immediately before September 2008.

In McAleer et al. (2009b), we developed a risk management strategy that used combinations of several models for forecasting VaR. It was found that an aggressive risk management strategy (namely, by choosing the infinum of $\mathrm{VaR}$ forecasts - upperbound) yielded the lowest mean capital charges, and had the highest frequency of minimizing daily capital charges throughout the forecasting period, but which also tended to violate too often. On the other hand, a conservative risk management strategy (namely, by choosing the supremum - 
lowerbound) had far fewer violations, and correspondingly higher mean daily capital charges. This can be seen in Table 3 below, taken from McAleer et al. (2009b).

\section{Table 3. Percentage of Days Minimizing Daily Capital Charges, Mean Daily Capital Charges, and Number of Violations for Alternative Models of Volatility}

$\begin{array}{lccc}\text { Model } & \begin{array}{c}\text { \% of Days } \\ \text { Minimizing } \\ \text { Daily Capital } \\ \text { Charges }\end{array} & \begin{array}{c}\text { Mean Daily } \\ \text { Capital } \\ \text { Charges }\end{array} & \begin{array}{c}\text { Number of } \\ \text { Violations }\end{array} \\ \text { Riskmetrics } & 14.0 \% & 0.163 & 10 \\ \text { GARCH } & 0.0 \% & 0.161 & 13 \\ \text { GJR } & 10.0 \% & 0.157 & 7 \\ \text { EGARCH } & 1.70 \% & 0.146 & 13 \\ \text { GARCH_t } & 0.00 \% & 0.171 & 3 \\ \text { GJR_t } & 0.00 \% & 0.167 & 3 \\ \text { EGARCH_t } & 34.0 \% & 0.153 & 3 \\ \text { Lowerbound } & 0.00 \% & 0.177 & 3 \\ \text { Upperbound } & 39.6 \% & 0.143 & 16\end{array}$

Note: the models of volatility chosen are the most frequently used in this literature. The figures are for the S\&P500 index from 2 January 2008 to 12 February 2009.

The area between the bounds provided by the aggressive and conservative risk management strategies would seem to be a fertile area for future research.

We could also compare the previous strategies with a dynamically learning strategy, DYLES, developed in McAleer et al. (2009a). For that strategy we disclose a market risk (MRD) that is the one given by a risk model that was modified by a weight factor $\mathrm{P}_{\mathrm{t}}$ :

$$
M R D_{t}=P_{t} \quad V a R_{t}
$$

where $\mathrm{P}_{\mathrm{t}}$ varies with the number of violations, to communicate risk to the monetary authorities. The variable $\mathrm{P}_{\mathrm{t}}$ is a measure of how conservative or aggressive the MRD is in comparison with the estimated risk: $\mathrm{P}_{\mathrm{t}}<1$ corresponds to an aggressive strategy because the MRD is below the estimated risk, whereas $P_{t}>1$ represents a conservative strategy (see McAleer et al. (2009b) for further details). 
The DYLES strategy leads to capital requirements that are significantly lower than those of competing models that stay within the Basel II limits. In particular, for a period of one year, when DYLES is used, it can improve on EGARCH t, which, as seen in Table 3, is one of the leading competitors, decreasing the average credit requirement by up to 96 basis points. See McAleer et al. (2009a).

The Basel II Accord is currently under scrutiny, with the purpose of enhancing its effectiveness for multinational financial regulation, as can be seen in the Consultative Document of the Basel Committee on Banking Supervision (2009). The Document contains proposals for changes to Pillars 1 to 3 , namely minimum capital requirements, supervisory review process and market discipline.

The Document discusses the application of more stringent risk weights, the management of liquidity risks and of solvency risks, and the use of stress tests (pages 2, 23 and 25), among other proposed regulatory measures.

\section{Conclusions}

In this paper we analysed the construction of risk management strategies that used combinations of several models for forecasting $\mathrm{VaR}$. It was found that an aggressive risk management strategy yielded the lowest mean capital charges, and had the highest frequency of minimizing daily capital charges throughout the forecasting period, but which also tended to violate too often. On the other hand, a conservative risk management strategy would yield far fewer violations, and correspondingly higher mean daily capital charge.

We also compared the previous two strategies with the DYLES strategy of McAleer et al. (2009a). In this case, we found slightly higher mean capital charges than the aggressive strategy, while the number of violations remained within the Basel II Accord limits.

The analysis presented above strongly suggests that, in seeking to manage market risk optimally, it can pay to vary risk management models on a daily basis.

\section{References}


Basel Committee on Banking Supervision, (1996), Supervisory Framework for the Use of "Backtesting” in Conjunction with the Internal Model-Based Approach to Market Risk Capital Requirements, BIS, Basel, Switzerland.

Basel Committee on Banking Supervision, (2009), Proposed enhancements to the Basel II framework, Consultative Document, BIS, Basel, Switzerland. (http://www.bis.org/publ/bcbs150.pdf?noframes=1)

Caporin, M. and M. McAleer (2009), The Ten Commandments for managing investments, to appear in Journal of Economic Surveys (Available at SSRN: http://ssrn.com/abstract=1342265).

Jiménez-Martín, J.-A., McAleer, M. and T. Pérez-Amaral (2009), The Ten Commandments for managing value-at-risk under the Basel II Accord, to appear in Journal of Economic Surveys (Available at SSRN: http://ssrn.com/abstract=1356803).

Jorion, P. (2000), Value at Risk: The New Benchmark for Managing Financial Risk, McGraw-Hill, New York.

McAleer, M. (2008), The Ten Commandments for optimizing value-at-risk and daily capital charges, to appear in Journal of Economic Surveys (Available at SSRN: http://ssrn.com/abstract=1354686).

McAleer, M., J.-Á. Jiménez-Martin and T. Pérez-Amaral (2009a), A decision rule to minimize daily capital charges in forecasting value-at-risk, Department of Quantitative Economics, Complutense University of Madrid, Spain (Available at SSRN: http://ssrn.com/abstract=1349844).

McAleer, M., J.-Á. Jiménez-Martin and T. Pérez-Amaral (2009b), Has the Basel II Accord Encouraged Risk Management During the 2008-09 Financial Crisis? , Department of Quantitative Economics, Complutense University of Madrid, Spain (Available at SSRN http://papers.ssrn.com/sol3/papers.cfm?abstract_id=1397239).

McAleer, M. and B. da Veiga (2008a), Forecasting value-at-risk with a parsimonious portfolio spillover GARCH (PS-GARCH) model, Journal of Forecasting, 27, 1-19.

McAleer, M. and B. da Veiga (2008b), Single index and portfolio models for forecasting value-at-risk thresholds, Journal of Forecasting, 27, 217-235. 